\title{
Anti-inflammatory effect of tranexamic acid against trauma-hemorrhagic shock-induced acute lung injury in rats
}

\author{
Yue TENG ${ }^{1,2) *}$, Cong FENG ${ }^{1) *}$, Yunen $\mathrm{LIU}^{2,3,4)}$, Hongxu JIN ${ }^{2)}$, Yan $\mathrm{GAO}^{2)}$, and Tanshi $\mathrm{LI}^{1)}$ \\ 1) Department of Emergency Medicine, Chinese PLA General Hospital, 28 Fuxing Road, Beijing 100853, P.R. China \\ ${ }^{2)}$ Department of Emergency Medicine, General Hospital of Shenyang Military Area Command, 83 Wenhua Road, \\ Shenyang 110016, P.R. China \\ ${ }^{3)}$ Laboratory of Rescue Center for Severe Wound and Trauma PLA, 83 Wenhua Road, Shenyang 110016, P.R. China \\ 4) Liaoning Key Laboratory of Severe Wound and Trauma and Organ Protection, 83 Wenhua Road, Shenyang 110016, \\ P.R. China
}

\begin{abstract}
It has been demonstrated that tranexamic acid (TXA), a synthetic derivative of lysine, alleviates lung damage in a trauma-hemorrhagic shock (T/HS) model. Nevertheless, the mechanism of TXA against acute lung injury (ALI) has not deeply elaborated. In this study, we generated a T/HS rat model based on previous research, and TXA (50 mg/kg and $100 \mathrm{mg} / \mathrm{kg}$ ) was intravenously injected into these rats prior to or post T/HS. The results revealed that the decreased survival rate and impaired lung permeability of the rats caused by T/HS were improved by TXA pretreatment or posttreatment. T/HS-triggered over-generation of interleukin-6 (IL-6) and tumor necrosis factor- $\alpha$ (TNF- $\alpha$ ) in bronchoalveolar fluid and serum was inhibited by TXA, and the enzymatic activity of myeloperoxidase (MPO) in lung tissues was suppressed by TXA as well. Furthermore, TXA treatment deactivated the poly ADP-ribose polymerase-1 (PARP1)/nuclear factor KB (NF-KB) signaling pathway in the lungs of T/HS rats, as evidenced by increased IKBa expression, and decreased cleaved PARP1, p-p65 (Ser276), p-p65 (Ser529), p-IkBa (ser32/ser36), and intercellular adhesion molecule-1. While the expression level of total p65 did not change after T/HS, its DNA binding activity was strengthened. Both TXA pretreatment and posttreatment suppressed this effect on the DNA binding activity of NFKB. Taken together, our results reveal that administration of TXA effectively relieves T/HS-induced $\mathrm{ALI}$, at least in part, by attenuating the abnormal pulmonary inflammation.
\end{abstract}

Key words: acute lung injury, hemorrhagic shock, inflammation, NF-kB, tranexamic acid

\section{Introduction}

Hemorrhagic shock caused by trauma (T/HS) is associated with a high mortality rate [7]. Serious T/HS can lead to ischemia-reperfusion injury of multiple organs with a systemic inflammatory response $[3,30]$. Acute lung injury (ALI) is one of the main complications of T/ HS, and it can deteriorate into acute respiratory distress syndrome (ARDS) [1]. Previous studies have demonstrated that intestinal ischemia induced by massive

(Received 14 November 2017 / Accepted 4 January 2018 / Published online in J-STAGE 2 February 2018)

Addresses corresponding: T. Li, Department of Emergency Medicine, Chinese PLA General Hospital, 28 Fuxing Road, Beijing 100853, P.R. China Y. Gao, Department of Emergency Medicine, General Hospital of Shenyang Military Area Command, 83 Wenhua Road, Shenyang 110016, P.R. China *Yue Teng and Cong Feng contributed equally to this study.

(c) $(-)$ This is an open-access article distributed under the terms of the Creative Commons Attribution Non-Commercial No Derivatives C. ${ }_{\mathrm{BY}} \mathrm{NC}_{\mathrm{ND}}(b y-n c-n d)$ License <http://creativecommons.org/licenses/by-nc-nd/4.0/>. 
bleeding causes damage to the gastrointestinal mucous membrane barrier, evoking enterogenous bacteremia and endotoxemia, eventually leading to ALI $[5,11]$. Hence, development of new drugs against inflammation may contribute to the treatment of T/HS with ALI.

Tranexamic acid (TXA) is a synthetic derivative of lysine that can suppress fibrinolysis and reduce blood loss by blocking the lysine-binding sites of plasminogen and plasmin [25]. Currently, TXA is widely used in blood disorders induced by various types of trauma, and its oral administration can decrease blood loss-induced mortality [14]. Peng et al. revealed that an enema of TXA relieved lung damage through activation of syndecan-1 in rats with hemorrhagic shock [24]. Moreover, TXA has been demonstrated to exert anti-inflammatory effects in multiple diseases $[4,6,15]$. Based on previous research, we speculate that TXA alleviates T/HS-associated ALI by attenuating pulmonary inflammation.

In the present study, to verify our hypothesis, rats were intravenously injected with TXA (50 mg/kg and $100 \mathrm{mg} /$ $\mathrm{kg}$ ) prior to or after $\mathrm{T} / \mathrm{HS}$. Then, the survival rate, lung permeability, and levels of inflammation-related factors in bronchoalveolar lavage fluid (BALF), serum, or lung tissues of these rats were evaluated. Furthermore, we explored the underlying molecular mechanisms of TXA against inflammation in rats with T/HS-triggered ALI.

\section{Materials and Methods}

\section{Animals and grouping}

Male Sprague Dawley rats weighing about $280 \pm 20$ g (10 weeks old) were purchased from Beijing HFK Bioscience Co., Ltd., (Beijing, China; Certificate No. SCXK (Jing) 2014-0004). The rats were housed in a light- and temperature-controlled room and allowed to eat and drink freely. This study was approved by the General Hospital of Shenyang Military Area Command and conducted according to the National Research Council's Guide for the Care and Use of Laboratory Animals.

All rats were randomly assigned to six groups (labeled as a, b, c, d, e, and f), and each group contained 28 rats: a, sham; b, T/HS group; c, pretreatment with TXA (50 $\mathrm{mg} / \mathrm{kg})+\mathrm{T} / \mathrm{HS}$ group; d, pretreatment with TXA (100 $\mathrm{mg} / \mathrm{kg})+\mathrm{T} / \mathrm{HS}$ group; e, T/HS + posttreatment with TXA $(50 \mathrm{mg} / \mathrm{kg})$ group; $\mathrm{f}, \mathrm{T} / \mathrm{HS}+$ posttreatment with TXA group $(100 \mathrm{mg} / \mathrm{kg})$. TXA was purchased from Aladdin Chemistry Co., Ltd. (Shanghai, China) and dissolved in sterile saline solution.

\section{Model of T/HS and treatment}

The model of T/HS was established by referring to previous studies [15, 31]. Briefly, the rats were anaesthetized by an intraperitoneal injection of pentobarbital sodium ( $50 \mathrm{mg} / \mathrm{kg}$ body weight) and fixed on an operating table. Then, a $0.5-\mathrm{cm}$ incision was made in the inguinal region, and both femoral arteries and the right jugular vein were exposed. The right femoral artery was linked to a blood pressure monitoring system (BL-420S, Taimeng Science Technology, Ltd., Chengdu, China) with a heparinized catheter. Blood was collected from the left femoral artery via a catheter. The right jugular vein was used for liquid administration. The rectal temperature was maintained at $37^{\circ} \mathrm{C}$ throughout the experiment. Afterwards, hemorrhagic shock was generated via withdrawal of blood and maintenance of the blood pressure at $30 \mathrm{mmHg}$ for $90 \mathrm{~min}$. Rats were intravenously injected with TXA prior to surgery in groups $\mathrm{c}$ and $\mathrm{d}$ and after surgery in groups e and $\mathrm{f}$.

After the above procedures, the rats were fed under the same conditions. Four hours later, 18 rats were randomly selected from each group: 6 rats were used for evaluation of lung permeability with Evans blue dye, and the other 12 (to obtain sufficient samples, each experimental group contained 6 rats) were used for collection of orbital blood, BALF, serum, and lung tissue samples. The remaining 10 rats in each group were used for survival analysis.

\section{Hematoxylin-eosin (HE) staining}

Tissue samples were routinely processed as paraffinembedded sections and cut to a thickness of $5 \mu \mathrm{m}$. The sections were dewaxed in xylene and hydrated in ethanol-water mixtures. Thereafter, they were soaked in hematoxylin solution for $5 \mathrm{~min}$, in hydrochloric acidalcohol solution for 3 seconds, and then in eosin for 5 $\min$. The sections were examined with a microscope (DP73, Olympus Corporation, Tokyo, Japan) following dehydration and sealing.

\section{Evans blue dye (EBD)}

Lung permeability was evaluated by EBD as described previously [27]. Briefly, rats in different groups were injected with $1 \mathrm{ml}$ of $1 \%$ EBD solution via the jugular vein. After $5 \mathrm{~min}$, a blood sample $(1.5 \mathrm{ml})$ was collected from the femoral artery catheter. Twenty minutes later, the rats were sacrificed, and the BALF was collected by rinsing the excised lungs with $5 \mathrm{ml}$ of normal saline 3 
times; the supernatant was gathered by centrifugation. The concentration of EBD in plasma and BALF was determined by detecting the absorbance value at $620 \mathrm{~nm}$ with a microplate reader (Elx800, BioTek, Winooski, VT, USA). The ratio of EBD in the BALF to that in the plasma was calculated.

\section{Lung permeability index}

Lung permeability index was calculated as the ratio of the BALF protein concentration to the serum protein concentration as described previously [20]. In brief, a portion $(1 \mu \mathrm{l})$ of sample supernatants was mixed with 4 $\mu 1$ normal saline and $250 \mu 1$ Coomassie brilliant blue G250. A microplate reader (BioTek) was used to measure the absorbance at $595 \mathrm{~nm}$. The protein concentration of BALF and plasma was computed based on the standard curve of bovine serum albumin (BSA).

Enzyme-linked immunosorbent assay (ELISA) and myeloperoxidase (MPO) activity

The content of interleukin-6 (IL-6) and tumor necrosis factor- $\alpha$ (TNF- $\alpha)$ in BALF and serum was detected with commercially available ELISA kits (Biotech Co., Ltd., Hangzhou, China) according to the manufacturer's protocols. The activity of MPO in lung tissues was measured using a commercial kit (Nanjing Jiancheng Bioengineering Institute, Nanjing, China) according to the manufacturer's instructions.

\section{Western blot}

The total protein was isolated from tissue samples using RIPA lysis buffer (Beyotime, Shanghai, China) containing the protease inhibitor PMSF. The protein concentration was determined using a BCA protein assay kit (Beyotime). Then, SDS-PAGE was carried out to separate protein fractions. The proteins were transferred to PVDF membranes (EMD Millipore, Bedford, MA, USA), and the membranes were blocked with 5\% skim milk and incubated with cleaved poly ADP-ribose polymerase-1 (PARP1) (CST, Danvers, MA, USA), p-p65 Ser276 (Bioss, Beijing, China), p-p65 Ser529 (Abcam, Cambridge, Great Britain), p65 (Bioss), p-IкB $\alpha$ Ser32/ Ser36 (Bioss), IкB $\alpha$ (Bioss), intercellular adhesion molecule-1 (ICAM-1) (Proteintech, Wuhan, China), and $\beta$-actin (Bioss) antibodies overnight at $4^{\circ} \mathrm{C}$. Thereafter, the primary antibodies were coupled with horseradish peroxidase-labeled goat anti-mouse or goat anti-rabbit second antibodies for $2 \mathrm{~h}$ at room temperature. Proteins were visualized by enhanced chemiluminescence (Beyotime) with a gel imaging system (Beijing Liuyi Instrument Factory, Beijing, China).

\section{Electrophoretic mobility shift assay (EMSA)}

An EMSA kit (Viagene Biotech, Inc., Tampa, FL, USA) was employed to examine active p65 according to the manufacturer's protocol. Briefly, the nuclear protein was extracted from tissue samples using a nuclear and cytoplasmic protein extraction kit (Beyotime), and the protein concentration was determined with a BCA protein assay kit (Beyotime). Five microliters of diluted protein $(5 \mu \mathrm{g} / \mu \mathrm{l})$ was mixed with $0.5 \mu$ l biotin-labeled NF- $\kappa$ B probe, $8 \mu 1$ double-distilled water, and $1.5 \mu 1$ reaction fluid $(10 \times)$. The reaction mixtures were electrophoresed on non-denaturing polyacrylamide gel. Then the protein-DNA complexes were transferred onto a membrane and cross-linked under an ultraviolet lamp for $30 \mathrm{~min}$. After incubation with HRP-conjugated streptavidin, the specific bands were visualized by enhanced chemiluminescence.

\section{Immunohistochemical analysis}

The expression levels of inducible nitric oxide synthase (iNOS), monocyte chemoattractant protein-1 (MCP-1), cyclooxygenase 2 (COX-2), and vascular cell adhesion molecule-1 (VCAM-1) were determined by immunohistochemical analysis. In brief, paraffin-embedded sections were subjected to antigen retrieval with citrate buffer following dewaxing and dehydration. Endogenous peroxidase activity was eliminated by incubation in $3 \% \mathrm{H}_{2} \mathrm{O}_{2}$. Then, the sections were sealed with goat serum and incubated with primary antibodies against iNOS (Proteintech), MCP-1 (abcam), COX-2 (Boster, Wuhan, China), and VCAM-1 (Proteintech) overnight at $4{ }^{\circ} \mathrm{C}$. The primary antibodies were probed with biotin-labeled goat anti-rabbit IgG. After incubation with horseradish peroxidase, counterstaining with hematoxylin, and coloration with $\mathrm{DAB}$, the sections were observed with a microscope (Olympus).

\section{Statistical analysis}

Each experiment was repeated three times except the survival analysis. The data were expressed as the mean \pm standard deviation (SD). Significant differences were analyzed by one-way analysis of variance followed by Tukey's multiple comparison test via the GraphPad Prism 7.0 software (GraphPad Software, La Jolla, CA, 
USA). A $P$ less than 0.05 was considered to indicate statistical significance.

\section{Results}

Administration of TXA raised the survival rate of T/HS rats

We first studied the effect of TXA on survival of T/ HS rats. As shown in Fig. 1, the survival rate of T/HS rats decreased by $50 \%$ at $24 \mathrm{~h}$ as compared with that of sham-operated rats. While pretreatment with 50 and 100 $\mathrm{mg} / \mathrm{kg}$ TXA increased the survival rate of T/HS rats by $10 \%$ and $30 \%$, respectively, posttreatment with $100 \mathrm{mg} /$ $\mathrm{kg}$ TXA increased it by $30 \%$. These data suggested a survival-promoting effect of TXA in T/HS rats.

\section{Administration of TXA alleviated ALI in T/HS rats}

We subsequently investigated the effects of TXA on T/HS-associated ALI. The results of HE staining showed that the lung tissues of T/HS rats were more compact than those of sham-operated rats and that TXA pretreatment $(50 \mathrm{mg} / \mathrm{kg}$ and $100 \mathrm{mg} / \mathrm{kg})$ or posttreatment (100 $\mathrm{mg} / \mathrm{kg}$ ) could alleviate such morphological changes (Fig. 2A). Moreover, lung permeability to EBD and the lung permeability index were assessed. As shown in Figs. 2B and $\mathrm{C}$, these two indicators were significantly increased after T/HS but were decreased by TXA treatments.

\section{Administration of TXA suppressed pulmonary inflammation of T/HS rats}

Next, we determined whether TXA had anti-inflammatory effects. As shown in Figs. 3A and B, the levels of IL- 6 and TNF- $\alpha$ in BALF and serum of T/HS rats were upregulated as compared with those of sham-operated rats. The elevation of these pro-inflammatory cytokines

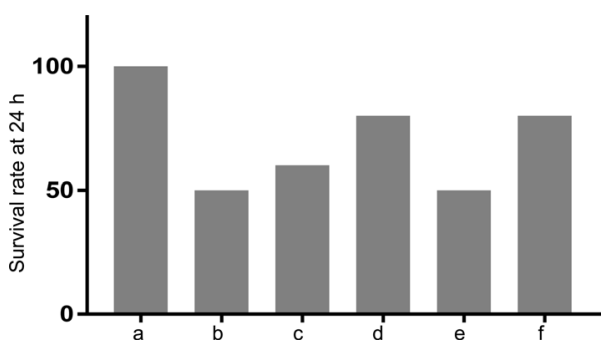

Fig. 1. Treatment with TXA increased the survival rate of rats with T/HS. The survival of rats following different experimental manipulations was evaluated. a, Sham; b, T/HS group; c, pretreatment with TXA (50 $\mathrm{mg} / \mathrm{kg})+\mathrm{T} / \mathrm{HS}$ group; d, pretreatment with TXA (100 mg/kg) + T/HS group; e, T/HS + posttreatment with TXA (50 mg/ $\mathrm{kg}$ ) group; f, T/HS + posttreatment with TXA group $(100 \mathrm{mg} / \mathrm{kg})$.

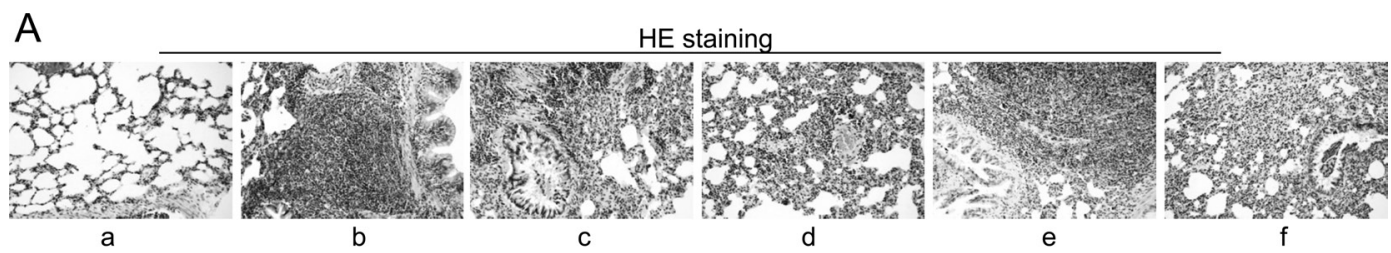

B

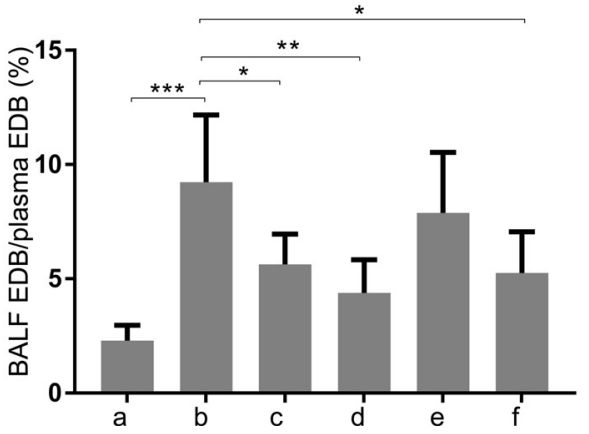

C

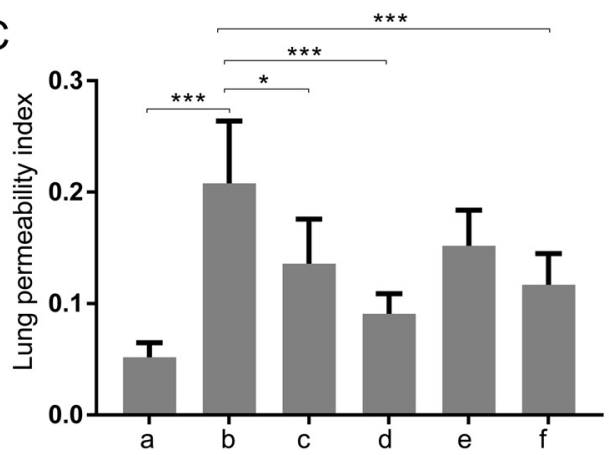

Fig. 2. Treatment with TXA relieved ALI of rats caused by T/HS. (A) Lung histological changes were examined by HE staining. (B) The ratio of the percentage of EBD in the BALF to EBD in the plasma. (C) Lung permeability index: BALF protein concentration /plasma protein concentration. a, Sham; b, T/HS group; , pretreatment with TXA $(50 \mathrm{mg} / \mathrm{kg})+$ T/HS group; d, pretreatment with TXA $(100 \mathrm{mg} / \mathrm{kg})+$ T/HS group; $\mathrm{e}, \mathrm{T} / \mathrm{HS}+$ posttreatment with TXA $(50 \mathrm{mg} / \mathrm{kg})$ group; $\mathrm{f}$ T/HS + posttreatment with TXA group (100 mg/ $\mathrm{kg}$ ). Data are presented as the mean $\pm \mathrm{SD} .{ }^{*} P<0.05 ; * * P<0.01 ; * * * P<0.001$. 

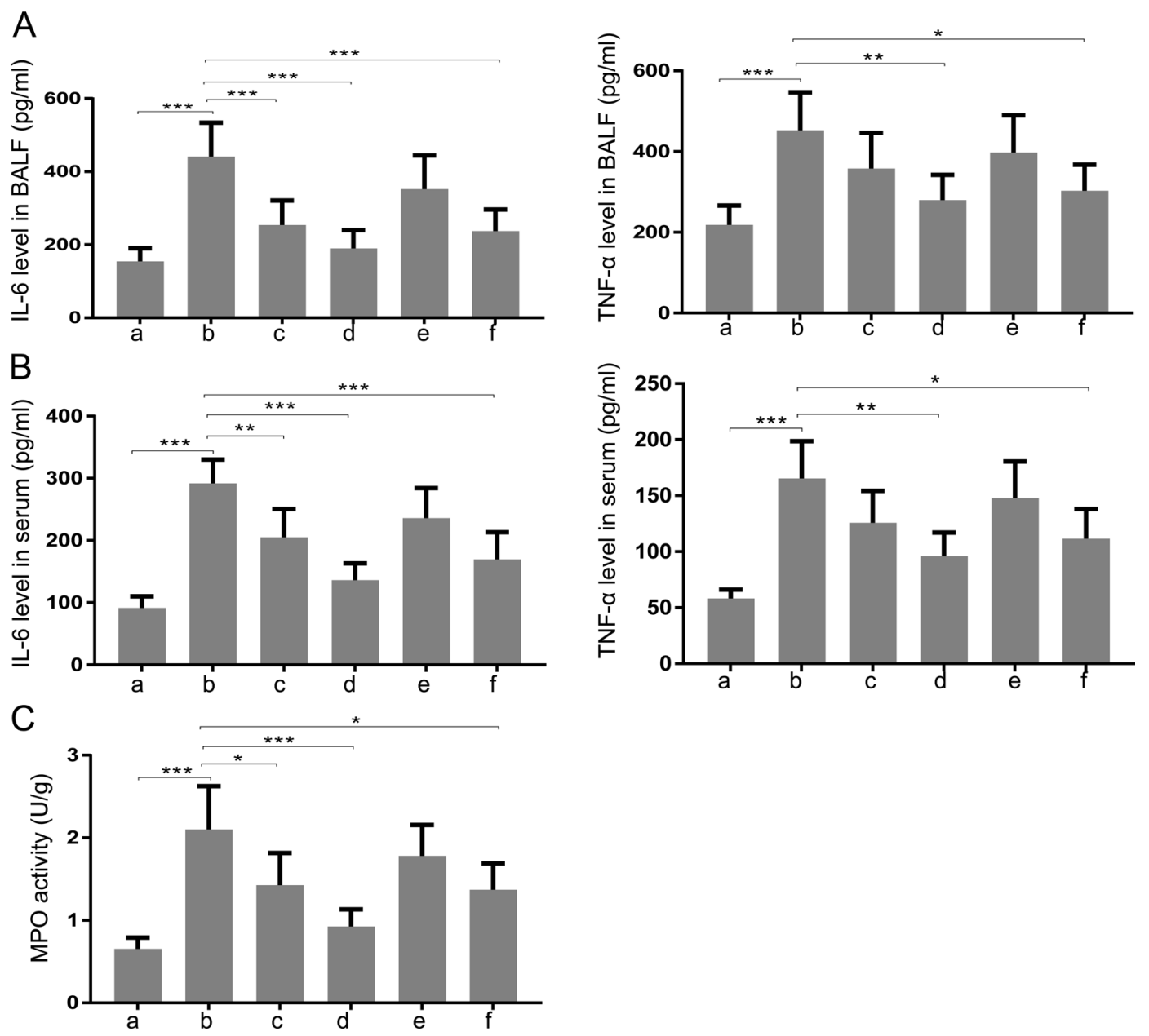

Fig. 3. Treatment with TXA inhibited inflammation of the lung in rats with T/HS. The levels of IL- 6 and TNF- $\alpha$ in (A) BALF and (B) serum were detected. (C) MPO activity in lung tissue was evaluated. a, Sham; b, T/ HS group; c, pretreatment with TXA $(50 \mathrm{mg} / \mathrm{kg})+$ T/HS group; d, pretreatment with TXA $(100 \mathrm{mg} / \mathrm{kg})+$ T/HS group; e, T/HS + posttreatment with TXA $(50 \mathrm{mg} / \mathrm{kg})$ group; $\mathrm{f}, \mathrm{T} / \mathrm{HS}+$ posttreatment with TXA group $(100 \mathrm{mg} / \mathrm{kg})$. Data are presented as the mean $\pm \mathrm{SD}$. ${ }^{*} P<0.05 ; * * P<0.01 ; * * * P<0.001$.

was suppressed by TXA pretreatment $(50 \mathrm{mg} / \mathrm{kg}$ and 100 $\mathrm{mg} / \mathrm{kg}$ ) or posttreatment $(100 \mathrm{mg} / \mathrm{kg})$. In addition, the enhanced enzymatic activity of MPO in lung tissues of T/HS rats was attenuated by TXA treatment (Fig. 3C).

\section{Administration of TXA deactivated the PARP1/NF- $\kappa B$ signaling pathway}

Finally, we explored the molecular mechanism of the anti-inflammation effects of TXA. As shown in Fig. 4A, western blot analysis showed that the increased levels of cleaved PARP1, p-p65 (Ser276), p-p65 (Ser529), $\mathrm{p}-\mathrm{I} \kappa \mathrm{B} \alpha$ (ser32/ser36), and ICAM-1 the decreased level of IкB $\alpha$ in lung tissues caused by T/HS were inhibited by TXA pretreatment $(50 \mathrm{mg} / \mathrm{kg}$ and $100 \mathrm{mg} / \mathrm{kg}$ ) or posttreatment $(100 \mathrm{mg} / \mathrm{kg})$. While the expression of total p65 did not change in all groups (Fig. 4A), the DNA binding activity of NF- $\mathrm{kB}$ was enhanced in T/HS lungs and suppressed by TXA treatment (Fig. 4B). Moreover, the expression levels of iNOS, MCP-1, COX-2, and VCAM1 in lung tissues of T/HS rats were upregulated, and these changes were inhibited as a result of TXA administration (Fig. 4C).

\section{Discussion}

Bleeding can be triggered by unexpected accidental trauma, but some bleeding is an expected consequence of special situations, such as cardiac surgery [19]. Thus, in this study TXA was given to some rats prior to T/HS to determine whether it could prevent bleeding-induced 


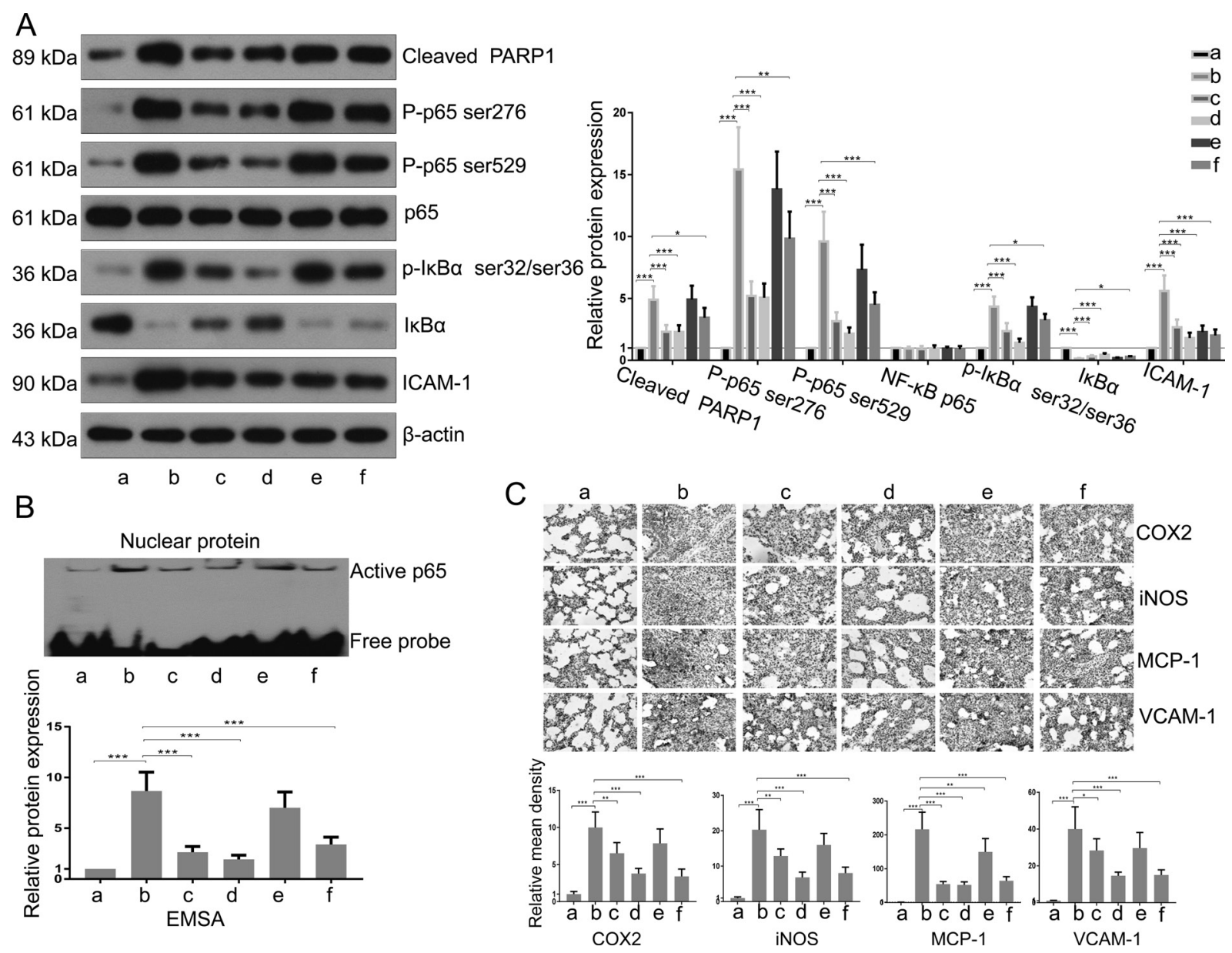

Fig. 4. Treatment with TXA attenuated the PARP1/NF- $\mathrm{BB}$ signaling pathway.(A) The expression levels of cleaved PARP1, p65,

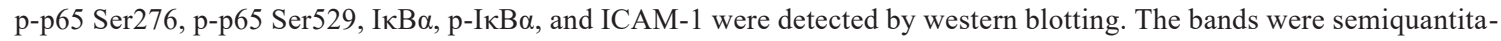
tively evaluated by densitometry, and the data were normalized to those of the internal control, $\beta$-actin. (B) Active p65 was examined through EMSA. The band (active p65) was semiquantitatively evaluated by densitometry. (C) The content of iNOS, MCP-1, COX-2, and VCAM-1 was determined by immunohistochemical analysis. The mean density of staining was calculated as the integrated optical density (IOD) sum/area. a, Sham; b, T/HS group; c, pretreatment with TXA (50 mg/kg) + T/HS group; d, pretreatment with TXA $(100 \mathrm{mg} / \mathrm{kg})+\mathrm{T} / \mathrm{HS}$ group; e, T/HS + posttreatment with TXA $(50 \mathrm{mg} / \mathrm{kg}) \mathrm{group}$; $\mathrm{f}, \mathrm{T} / \mathrm{HS}+$ posttreatment with TXA group $(100 \mathrm{mg} / \mathrm{kg})$. Data are presented as the mean $\pm \mathrm{SD}$. ${ }^{*} P<0.05 ; * * P<0.01 ; * * * P<0.001$.

ALI. Our results showed that TXA pretreatments of 50 or $100 \mathrm{mg} / \mathrm{kg}$ improved the survival rate, inhibited pulmonary inflammation, and deactivated the PARP1/NF$\kappa \mathrm{B}$ pathway in T/HS rats. As for the posttreatment, only the higher dose of TXA showed survival-promoting and lung-protective effects. These data suggested that giving TXA to patients prior to T/HS assault was a better choice.

The molecular mechanism of ALI after T/HS is very complicated. It has been demonstrated that the intestinal mucosal barrier was destroyed after T/HS. Subsequently, the bacteria spread to the bloodstream, leading to systemic inflammatory response syndrome (SIRS) [8, 23]. During the development of SIRS, many pro-inflam- matory cytokines are released excessively, including TNF- $\alpha$ and IL-6 [28]. The activity of MPO, an enzyme secreted by various inflammatory cells, was upregulated during the inflammatory response [32]. Our data here illustrated that TXA could inhibit over-generation of TNF- $\alpha$ and IL- 6 in BALF and serum and suppress MPO activity in the lung tissues of T/HS rats, indicating that TXA exerted anti-inflammatory effects in experimental ALI.

Multiple pathways are involved in the inflammatory response, such as mitogen-activated protein kinase (MAPK) [17], phosphoinositide 3-kinase (PI3K) [12], Akt [29], and mammalian target of rapamycin (mTOR) 
[9]. Moreover, several previous studies have demonstrated that aberrant activation of pro-inflammatory tolllike receptor-4 (TLR4) [26], high-mobility group box 1 (HMGB1) [16], and NF-kB [21] pathways is linked to T/HS-associated ALI. NF- $\kappa B$ is a family that contains

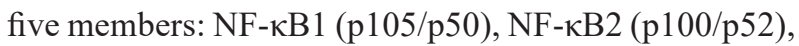
RelA (p65), RelB, and c-Rel. These members constitute various active $\mathrm{NF}-\kappa \mathrm{B}$ heterodimers that bind to specific DNA sequences of their target genes at the promoter region. NF- $\mathrm{kB}$ can be activated by multiple stress stimuli (such as TNF- $\alpha$ and IL-6) via degradation of IкB proteins. The activated NF- $\kappa B$ rapidly translocates to the nucleus, where it initiates the expression of its downstream targets and proinflammatory cytokines $[2,10$, 13]. In turn, the pro-inflammatory cytokines, including TNF- $\alpha$ and IL-6, activate the NF- $\kappa$ B pathway, amplifying the inflammatory response [22]. Our study demonstrated that TXA could inhibit T/HS-induced activation of the NF-KB pathway in rat lungs, as evidenced by the increased IкB $\alpha$ expression and decreased p-p65 (Ser276), p-p65 (Ser529), p-IкB $\alpha$ (ser32/ser36), and active p65 expression. The amount of total p65 did not change post $\mathrm{T} / \mathrm{HS}$, but the DNA binding activity of NF- $\mathrm{KB}$ was enhanced, suggesting that $\mathrm{T} / \mathrm{HS}$ could induce the release of $\mathrm{p} 65$ from its inhibitor IкB $\alpha$ [18]. The activated NF- $\kappa B$ signaling in the rat lung was inhibited by TXA. The elevation of NF- $\kappa \mathrm{B}$ downstream target genes ICAM-1, iNOS, MCP-1, COX-2, and VCAM-1 in T/HS rats was also suppressed by TXA. In addition, the cleaved level of PARP1, a factor known to promote NF-kB nuclear retention [33], was decreased by TXA as well.

Taken together, our results demonstrate that the survival-promoting effects of TXA given prior to or post T/ HS are associated with its anti-inflammatory action in the lung. TXA can attenuate the over-activation of the pro-inflammatory PARP1/NF- $\kappa B$ pathway as well.

\section{Conflict of Interest}

The authors declare that they have no conflicts of interest.

\section{Acknowledgments}

This study was supported by grants from the Welfare Industry Research Program of the Ministry of Health (No. 201502019), the National Natural Science Foundation of China (Nos. 81371561 and 81701961), the PLA
General Hospital Science and Technology Project (Nos. 16KMM56 and 2017FC-WJFWZX-30), and the PLA Logistic Major Science and Technology Project (Nos. 14CXZ005, AWS15J004, BWS14J041, and 16QNP135). The authors are grateful to High-tech Zone Laboratory of Public Test and Analysis Service (Shenyang, China) for English editing.

\section{References}

1. Ananthakrishnan, P., Cohen, D.B., Xu, D.Z., Lu, Q., Feketeova, E., and Deitch, E.A. 2005. Sex hormones modulate distant organ injury in both a trauma/hemorrhagic shock model and a burn model. Surgery 137: 56-65. [Medline] [CrossRef]

2. Baker, R.G., Hayden, M.S., and Ghosh, S. 2011. NF-кB, inflammation, and metabolic disease. Cell Metab. 13: 11-22. [Medline] [CrossRef]

3. Botha, A.J., Moore, F.A., Moore, E.E., Sauaia, A., Banerjee, A., and Peterson, V.M. 1995. Early neutrophil sequestration after injury: a pathogenic mechanism for multiple organ failure. J. Trauma 39: 411-417. [Medline] [CrossRef]

4. Boudreau, R.M., Johnson, M., Veile, R., Friend, L.A., Goetzman, H., Pritts, T.A., Caldwell, C.C., Makley, A.T., and Goodman, M.D. 2017. Impact of tranexamic acid on coagulation and inflammation in murine models of traumatic brain injury and hemorrhage. J. Surg. Res. 215: 47-54. [Medline] [CrossRef]

5. Burck, R. 2004. Challenges of treating on the basis of knowledge: The ARDS Network trials and the ensuing controversy. Crit. Care Med. 32: 904-905. [Medline] [CrossRef]

6. Chen, T.T., Jiandong-Liu., Wang, G., Jiang, S.L., Li, L.B., and Gao, C.Q. 2013. Combined treatment of ulinastatin and tranexamic acid provides beneficial effects by inhibiting inflammatory and fibrinolytic response in patients undergoing heart valve replacement surgery. Heart Surg. Forum 16: E38-E47. [Medline] [CrossRef]

7. Cherkas, D. 2011. Traumatic hemorrhagic shock: advances in fluid management. Emerg. Med. Pract. 13: 1-19, quiz 19-20. [Medline]

8. Diebel, M.E., Diebel, L.N., and Liberati, D.M. 2017. Tranexamic acid and the gut barrier: Protection by inhibition of trypsin uptake and activation of downstream intestinal proteases. Am. J. Surg. 213: 489-493. [Medline] [CrossRef]

9. Gao, S., Liu, W., Zhuo, X., Wang, L., Wang, G., Sun, T., Zhao, Z., Liu, J., Tian, Y., Zhou, J., Yuan, Z., and Wu, Y. 2015. The activation of mTOR is required for monocyte proinflammatory response in patients with coronary artery disease. Clin. Sci. 128: 517-526. [Medline] [CrossRef]

10. Gasparini, C. and Feldmann, M. 2012. NF- $\kappa B$ as a target for modulating inflammatory responses. Curr. Pharm. Des. 18: 5735-5745. [Medline] [CrossRef]

11. Goodman, R.B., Pugin, J., Lee, J.S., and Matthay, M.A. 2003. Cytokine-mediated inflammation in acute lung injury. Cytokine Growth Factor Rev. 14: 523-535. [Medline] [CrossRef] 
12. Hawkins, P.T. and Stephens, L.R. 2015. PI3K signalling in inflammation. Biochim. Biophys. Acta 1851: 882-897. [Medline] [CrossRef]

13. Hoesel, B. and Schmid, J.A. 2013. The complexity of NF- $\kappa B$ signaling in inflammation and cancer. Mol. Cancer 12: 86. [Medline] [CrossRef]

14. Irwin, A., Khan, S.K., Jameson, S.S., Tate, R.C., Copeland, C., and Reed, M.R. 2013. Oral versus intravenous tranexamic acid in enhanced-recovery primary total hip and knee replacement: results of 3000 procedures. Bone Joint J. 95-B: 1556-1561. [Medline] [CrossRef]

15. Jimenez, J.J., Iribarren, J.L., Lorente, L., Rodriguez, J.M., Hernandez, D., Nassar, I., Perez, R., Brouard, M., Milena, A., Martinez, R., and Mora, M.L. 2007. Tranexamic acid attenuates inflammatory response in cardiopulmonary bypass surgery through blockade of fibrinolysis: a case control study followed by a randomized double-blind controlled trial. Crit. Care 11: R117. [Medline] [CrossRef]

16. Kim, J.Y., Park, J.S., Strassheim, D., Douglas, I., Diaz del Valle, F., Asehnoune, K., Mitra, S., Kwak, S.H., Yamada, S., Maruyama, I., Ishizaka, A., and Abraham, E. 2005. HMGB1 contributes to the development of acute lung injury after hemorrhage. Am. J. Physiol. Lung Cell. Mol. Physiol. 288: L958-L965. [Medline] [CrossRef]

17. Kong, L., Liu, J., Wang, J., Luo, Q., Zhang, H., Liu, B., Xu, F., Pang, Q., Liu, Y., and Dong, J. 2015. Icariin inhibits TNF- $\alpha / \mathrm{IFN}-\gamma$ induced inflammatory response via inhibition of the substance P and p38-MAPK signaling pathway in human keratinocytes. Int. Immunopharmacol. 29: 401-407. [Medline] [CrossRef]

18. Lee, S.J., Rim, H.K., Jung, J.Y., An, H.J., Shin, J.S., Cho, C.W., Rhee, Y.K., Hong, H.D., and Lee, K.T. 2013. Immunostimulatory activity of polysaccharides from Cheonggukjang. Food Chem. Toxicol. 59: 476-484. [Medline] [CrossRef]

19. Levkovich, B.J., Bui, T., Bovell, A., Watterson, J., Egan, A., Poole, S.G., and Dooley, M.J. 2016. Variability of intravenous medication preparation in Australian and New Zealand intensive care units. J. Eval. Clin. Pract. 22: 965-970. [Medline] [CrossRef]

20. Liu, W.J., Zhong, Z.J., Cao, L.H., Li, H.T., Zhang, T.H., and Lin, W.Q. 2015. Paclitaxel-induced lung injury and its amelioration by parecoxib sodium. Sci. Rep. 5: 12977. [Medline] [CrossRef]

21. Liu, X., Zhang, J., Han, W., Wang, Y., Liu, Y., Zhang, Y., Zhou, D., and Xiang, L. 2017. Inhibition of BTK protects lungs from trauma-hemorrhagic shock-induced injury in rats. Mol. Med. Rep. 16: 192-200. [Medline] [CrossRef]

22. Miyata, K., Yotsumoto, F., Nam, S.O., Kuroki, M., and Miyamoto, S. 2012. Regulatory mechanisms of the HB-EGF autocrine loop in inflammation, homeostasis, development and cancer. Anticancer Res. 32: 2347-2352. [Medline]

23. Olanders, K., Sun, Z., Börjesson, A., Dib, M., Andersson,
E., Lasson, A., Ohlsson, T., and Andersson, R. 2002. The effect of intestinal ischemia and reperfusion injury on ICAM1 expression, endothelial barrier function, neutrophil tissue influx, and protease inhibitor levels in rats. Shock 18: 86-92. [Medline] [CrossRef]

24. Peng, Z., Ban, K., LeBlanc, A., and Kozar, R.A. 2016. Intraluminal tranexamic acid inhibits intestinal sheddases and mitigates gut and lung injury and inflammation in a rodent model of hemorrhagic shock. J. Trauma Acute Care Surg. 81: 358-365. [Medline] [CrossRef]

25. Rappold, J.F. and Pusateri, A.E. 2013. Tranexamic acid in remote damage control resuscitation. Transfusion 53:(Suppl 1): 96S-99S. [Medline] [CrossRef]

26. Reino, D.C., Pisarenko, V., Palange, D., Doucet, D., Bonitz, R.P., Lu, Q., Colorado, I., Sheth, S.U., Chandler, B., Kannan, K.B., Ramanathan, M., Xu, D.Z., Deitch, E.A., and Feinman, R. 2011. Trauma hemorrhagic shock-induced lung injury involves a gut-lymph-induced TLR4 pathway in mice. PLoS One 6: e14829. [Medline] [CrossRef]

27. Shi, H.P., Deitch, E.A., Da Xu, Z., Lu, Q., and Hauser, C.J. 2002. Hypertonic saline improves intestinal mucosa barrier function and lung injury after trauma-hemorrhagic shock. Shock 17: 496-501. [Medline] [CrossRef]

28. Tsukamoto, T., Chanthaphavong, R.S., and Pape, H.C. 2010. Current theories on the pathophysiology of multiple organ failure after trauma. Injury 41:21-26. [Medline] [CrossRef]

29. Vo, V.A., Lee, J.W., Kim, J.Y., Park, J.H., Lee, H.J., Kim, S.S., Kwon, Y.S., and Chun, W. 2014. Phosphorylation of Akt Mediates Anti-Inflammatory Activity of 1-p-Coumaroyl $\beta$-D-Glucoside Against Lipopolysaccharide-Induced Inflammation in RAW264.7 Cells. Korean J. Physiol. Pharmacol. 18: 79-86. [Medline] [CrossRef]

30. Weiss, S.J. 1989. Tissue destruction by neutrophils. N. Engl. J. Med. 320: 365-376. [Medline] [CrossRef]

31. Yang, R., Gallo, D.J., Baust, J.J., Uchiyama, T., Watkins, S.K., Delude, R.L., and Fink, M.P. 2002. Ethyl pyruvate modulates inflammatory gene expression in mice subjected to hemorrhagic shock. Am. J. Physiol. Gastrointest. Liver Physiol. 283: G212-G221. [Medline] [CrossRef]

32. Ye, S., Zhu, Y., Ming, Y., She, X., Liu, H., and Ye, Q. 2014. Glycyrrhizin protects mice against renal ischemia-reperfusion injury through inhibition of apoptosis and inflammation by downregulating p38 mitogen-activated protein kinase signaling. Exp. Ther. Med. 7: 1247-1252. [Medline] [CrossRef]

33. Zerfaoui, M., Errami, Y., Naura, A.S., Suzuki, Y., Kim, H., Ju, J., Liu, T., Hans, C.P., Kim, J.G., Abd Elmageed, Z.Y., Koochekpour, S., Catling, A., and Boulares, A.H. 2010. Poly(ADP-ribose) polymerase-1 is a determining factor in Crm1-mediated nuclear export and retention of p65 NF-kappa B upon TLR4 stimulation. J. Immunol. 185: 1894-1902. [Medline] [CrossRef] 